\section{Jukyeom as the Source of Trace Elements to the Human Body: An Analysis using In- san Jukyeom}

\author{
Yoon-Chul Lee ${ }^{1 *}$, Min-Sun Lee ${ }^{2}$ and Seok-Jong Jang ${ }^{3}$ \\ ${ }^{1}$ Department of Naturopathy, Dongbang University of graduate school, \\ South Korea \\ ${ }^{2}$ Graduate School of Integrative Medicine, Sun Moon University, Asan, \\ Chungcheongnam-do, South Korea
}

${ }^{3}$ Graduate School Naturopathy in Mission, Seoul Jang Sin University, Gwangju, Gyeonggi, South Korea

\begin{abstract}
Jukyeom is a solar salt roasted in bamboo. Although the safety and role of Jukyeom as the source of nutrient is well examined in the exiting literatures, the exact composition of Jukyeom and its potential role as the source of trace elements to a human body has not been examined. This study conducts an elemental analysis to examine Jukyeom as the source of trace elements to human body, which includes all of 60 elements (focuses on 54 measurable elements) of components of a human body. This study also verifies that Jukyeom has different characteristics from solar sodium. This difference might be due to the production process of Jukyeom, which is involved with ripening of solar sodium, heat treatment based on bamboos, red clay, and pine resin. Based on ICP-MS with other proper methods, Jukyeom contains all trace elements of the human body while their concentration levels and composition ratios are different.
\end{abstract}

Keywords: Jukyeom; In-san jukyeom; Trace element; Solar sodium

\section{Introduction}

Dietary mineral composes about $4 \%$ of the human body. Because we are not able to produce minerals within our bodies, we must obtain them through our food. Minerals act as co-factors for enzyme reactions and maintain the $\mathrm{pH}$ balance of the human body. They also facilitate the transfer of nutrients across cells and maintain proper nerve conduction. If dietary minerals are deficient, the functions of the human cell and organs are deteriorated [1]. Such deficiencies also probably cause cancers or other chronic disease. Without these trace

${ }^{*}$ Corresponding author: Yoon-Chul Lee, Department of Naturopathy, Dongbang University of graduate school, South Korea, South Korea, Tel: +82 01042096588 , E-mail: profjjlee@naver.com

Citation: Yoon-Chul Lee, Min-Sun Lee, Seok-Jong Jang (2016) Jang Jukyeom as the Source of Trace Elements to the Human Body: An Analysis using In-san Jukyeom. J Food Sci Nutr 2: 011.

Received: July 26, 2016; Accepted: August 19, 2016; Published: September 05, 2016 minerals, it is hard to sustain our lives, even though the amounts of these minerals are minuscule [2]. P. A. Balch asserts that the human body must maintain its proper chemical balance. This balance depends on the levels of different minerals in the body and especially the ratios of certain mineral levels to one another. The level of each mineral in the body has an effect on every other one, so if one is out of balance, all mineral levels are affected. If the level is not corrected, this can start a chain reaction of imbalances that leads to illness [3].

According to the Senate document No. 264, however, more than 99\% of Americans experience deficiencies of dietary mineral, which also potentially deteriorates the function of vitamins. The document points out that all of the vegetables, fruits and meats of our generation are quite different from those in a few generations ago. Therefore, the modern foods contain very low level of minerals compared to the same food in decades ago [4]. The U.S. department of agriculture confirms this tendency. More than $40 \%$ of Americans consume minerals less than $60 \%$ of the dietary reference intakes. More than $50 \%$ of American people lack of vitamin B6. About $42 \%$ of them are deficient in the intake of calcium and about $39 \%$ of them experience lack of iron intakes [5].

Wesley Jarrell claims that the reduction of nutrients in fruits and vegetables results from the widespread use of chemical fertilizers and agricultural pesticides due to the agricultural revolution. He argues that water content in fruits and vegetables has increased after the agricultural revolution but minerals and vitamins have decreased substantially, especially due to the prevalent use of chemical fertilizers [6]. Accordingly, it is hard to provide trace elements to the human body via the intake of food, which emphasizes the need of nutritional supplements containing a variety of trace elements.

Solar salt is considered as one of candidates for the mineral supplements to the human body. Prior literature has argued the similarity in between the compositional elements of human body and the elements contained in sea salt [7]. Some Japanese studies confirmed this similarity by using the sea water sample from Hokaido. They actually identified 83 elements in sea water [8].

Moreover, the existing literatures [9] found that the human body contains toxic elements such as Barium, Mercury, Antimony, Thallium, Thorium, Uranium, Beryllium and Radium, similar to the contents of sea water. The human body also contains and metabolizes Oxygen, Fluorine, Lead, Cadmium, Selenium, Arsenic and Lithium, which endanger the human health condition with excess intakes in table 1. In particular, the human body includes some carcinogens such as Lead, Aluminum, Cadmium, Selenium, Arsenic, Mercury, Thorium, Beryllium and Radium based on the criterion of International Agency for Research on Cancer in table 2. These existences are probably due to the origin of the earth and the human body. The early stage of the earth already had these elements and other heavy metals and the human body has naturally incorporated these toxins in the process of its evolution [10].

Jukyeom is a solar salt roasted in bamboo. Solar salt is stuffed into bamboo tubes, and the ends plugged with mud. This assembly is 
Citation: Yoon-Chul Lee, Min-Sun Lee, Seok-Jong Jang (2016) Jang Jukyeom as the Source of Trace Elements to the Human Body: An Analysis using In-san Jukyeom. J Food Sci Nutr 2: 011.

- Page 2 of 7 •

\begin{tabular}{|c|c|c|c|c|c|c|}
\hline \multirow[b]{2}{*}{ No } & \multicolumn{4}{|c|}{ Composition of the human body ${ }^{11)}$} & \multirow{2}{*}{$\begin{array}{l}\text { Concentration in } \\
\text { Jukyeom }{ }^{2 / 2}\end{array}$} & \multirow[b]{2}{*}{ Negative effects } \\
\hline & Element & $\begin{array}{c}\text { Fraction of } \\
\text { mass }\end{array}$ & Mass (kg) & $\begin{array}{l}\text { Atomic per- } \\
\text { cent }\end{array}$ & & \\
\hline 1 & O (Oxygen) & 0.65 & 43 & 24 & & Reactive Oxygen Species \\
\hline 2 & F (Fluorine) & $37 \times 10^{-6}$ & 0.0026 & 0.0012 & $<17 \mathrm{ppm}$ & Toxic in higher amounts \\
\hline 3 & $\mathrm{~Pb}($ Lead) & $1.7 \times 10^{-6}$ & 0.00012 & 0.0000045 & $<0.385 p p m$ & Toxic in higher amounts \\
\hline 4 & $\mathrm{Cd}$ (Cadmium) & $720 \times 10^{-9}$ & 0.000050 & 0.0000045 & $<0.385 \mathrm{ppm}$ & Toxic in higher amounts \\
\hline 5 & $\mathrm{Ba}$ (Barium) & $310 \times 10^{-9}$ & 0.000022 & 0.0000012 & $6.21 \mathrm{ppm}$ & Toxic \\
\hline 6 & Se (Selenium) & $190 \times 10^{-9}$ & 0.000015 & 4.e-8 & $<2.84 \mathrm{ppm}$ & Toxic in higher amounts \\
\hline 7 & As (Arsenic) & $260 \times 10^{-9}$ & 0.000007 & $8.9 \mathrm{e}-8$ & $<1.93 \mathrm{ppm}$ & Toxic in higher amounts \\
\hline 8 & Li (Lithium) & $31 \times 10^{-9}$ & 0.000007 & 0.0000015 & $<14.3 \mathrm{ppm}$ & Toxic in higher amounts \\
\hline 9 & $\mathrm{Hg}$ (Mercury) & $190 \times 10^{-9}$ & 0.000006 & $8.9 \mathrm{e}-8$ & $<0.712 \mathrm{ppm}$ & Toxic \\
\hline 10 & $\mathrm{Sb}$ (Antimony) & $110 \times 10^{-9}$ & 0.000002 & - & $<0.389 \mathrm{ppm}$ & Toxic \\
\hline 11 & $\mathrm{TI}$ (Thallium) & - & $5 e-7$ & - & $<0.961 \mathrm{ppm}$ & Toxic \\
\hline 12 & Th (Thorium) & - & $1 \mathrm{e}-7$ & - & $<0.385 \mathrm{ppm}$ & Toxic \\
\hline 13 & U (Uranium) & $1.3 \times 10^{-9}$ & $1 e-7$ & $3.0 \mathrm{e}-9$ & $<0.385 \mathrm{ppm}$ & Toxic \\
\hline 14 & Be (Beryllium) & $50 \times 10^{-12}$ & $3.6 e-8$ & $4.5 \mathrm{e}-8$ & $<14.3 \mathrm{ppm}$ & Toxic \\
\hline 15 & Ra (Radium) & $1 \times 10^{-19}$ & $3 e-14$ & $1 e-17 \%$ & - & Toxic \\
\hline 16 & Po (Polonium) & - & $6.8 \mathrm{e} 15[5]$ & - & - & Toxic \\
\hline
\end{tabular}

Table 1: Toxic ingredients in the composition of the human body (average $70 \mathrm{~kg}$ adult).

*1) Composition of the human body -Elemental composition list- Wikipedia

*2) GLI's Laboratory Report No.82973 (2015. 09. 01)

\begin{tabular}{|c|c|c|c|c|c|}
\hline \multirow{2}{*}{ IARC Group } & \multicolumn{2}{|c|}{ Human body (average 70kg adult) } & \multirow{2}{*}{ Concentration in Jukyeom ${ }^{* 2)}$} & \multicolumn{2}{|c|}{ KFDA's Allowance } \\
\hline & Element & Fraction of mass & & As Table Salt $(\mathrm{mg} / \mathbf{k g})^{* 3)}$ & As Health Functional Food $(\mu \mathrm{g} / \text { day })^{* 4)}$ \\
\hline $2 \mathrm{~B}$ & $\mathrm{~Pb}$ (Lead) & 0.00012 & $<0.385 \mathrm{ppm}$ & $2.0 \geq$ & $<0.18$ \\
\hline 1 & Cd (Cadmium) & 0.000050 & $<0.385 p p m$ & $0.5 \geq$ & $<3.0$ \\
\hline $2 \mathrm{~B}$ & $\mathrm{Ni}$ (Nickel) & 0.000015 & 0.980ppm & \multicolumn{2}{|c|}{ No legal provision } \\
\hline 1 & As (Arsenic) & 0.000007 & $<1.93 p p m$ & $0.5 \geq$ & $<150$ \\
\hline 2B & Co (Cobalt) & 0.000003 & $<0.385 \mathrm{ppm}$ & \multicolumn{2}{|c|}{ No legal provision } \\
\hline 1 & Th (Thorium) & $1 e-7$ & $<0.385 \mathrm{ppm}$ & \multicolumn{2}{|c|}{ No legal provision } \\
\hline 1 & Be (Beryllium) & $3.6 e-8$ & $<14.3 p p m$ & \multicolumn{2}{|c|}{ No legal provision } \\
\hline 1 & Ra (Radium) & $3 e-14$ & - & \multicolumn{2}{|c|}{ Exception of analysis } \\
\hline *5) & $\mathrm{Hg}$ (Mercury) & 0.000006 & $<0.7123 \mathrm{ppm}$ & $0.1 \geq$ & $<2.1$ \\
\hline
\end{tabular}

Table 2: Carcinogens in the composition of the human body ${ }^{* 11}$.

*1) Agents Classified by the IARC (International Agency for Research on Cancer) Monographs, Volume 1-112

*2) GLI'S Laboratory Report No.83233 (2015. 09. 11)

*3) KFDA'S Korean Food Standards Codex Item 29-12, 2015.5, pp. 196 197

*4) KFDA'S Korean Health Functional Food Codex Attached Table 3, 2015. 1, p. 175

*5) Mercury is not classified as a carcinogen by IARC, but is designated as a hazardous heavy metals by KFDA

\begin{tabular}{|c|c|c|c|}
\hline Concentration (\%) & Jukyeom & Taean Chonilyom & Shinan Chonilyom \\
\hline $0.9 \%$ solution & 9.57 & 8.79 & 7.23 \\
$10 \%$ solution & 10.27 & 0.01 & 8.38 \\
$20 \%$ solution & 10.47 & 8.87 & 8.30 \\
\hline
\end{tabular}

Table 3: $\mathrm{pH}$ Test result of the Jukyeom ${ }^{* 11}$.

*1) GLI's Laboratory Report No.85449 (2015. 12. 09), Lab. ID: 2015-A-3330

roasted one or more times. In the case of In-san Jukyeom, this assembly is roasted nine times ( 8 times at $800^{\circ} \mathrm{C}$ and lastly at $1,300^{\circ} \mathrm{C}$ ). Table 4 shows the components of Jukyeom comparing with human body elements.

Prior literatures confirm the safety of Jukyeom intake to the human body. Shin et al., verify through single dose toxicity studies that one time intake of $153.6 \mathrm{~g}$ of Jukyeom does not cause any harmful effects to the human body for an adult with weight of $60 \mathrm{~kg}$ [11]. Kim et al., found no significantly harmful effects to the human body after $120 \mathrm{~g}$ of daily Jukyeom intake for two weeks, except minor lesions [12]
Kim et al., show that a daily Jukyeom intake of $180 \mathrm{~g}$ for 90 days does not cause considerably harmful effects to the human body [13].

The existing studies also confirm that the intake of Jukyeom is also genetically safe. Lee et al., conduct Chromosom alanomaly test of Jukyeom by using the lung of Chinese hamsters. Both analyses using direct method and the S9 metabolic activation system show that less than $5 \%$ of genetic mutations in CHL cells argue against the possibility of genetic mutations form Jukyeom intake [14]. Their micronucleus test also confirms no genotoxicity of Jukyeom in bone marrow cells of mice [15].

Lee et al., conduct bacterial reverse mutation test of Jukeyom by using Salmonella Typhimurium TA100, TA1535, Escherichia coli WP2uvrA, Salmonella TA98, and TA1537. Their results based on the treatment and control groups indicate no significantly genetoxicities of Jukyeom [16].

All salts involved in the numerous salt hypertension arguments were refined salts, which is pure $\mathrm{NaCl}$ without any other minerals. 
Citation: Yoon-Chul Lee, Min-Sun Lee, Seok-Jong Jang (2016) Jang Jukyeom as the Source of Trace Elements to the Human Body: An Analysis using In-san Jukyeom. J Food Sci Nutr 2: 011.

- Page 3 of 7 •

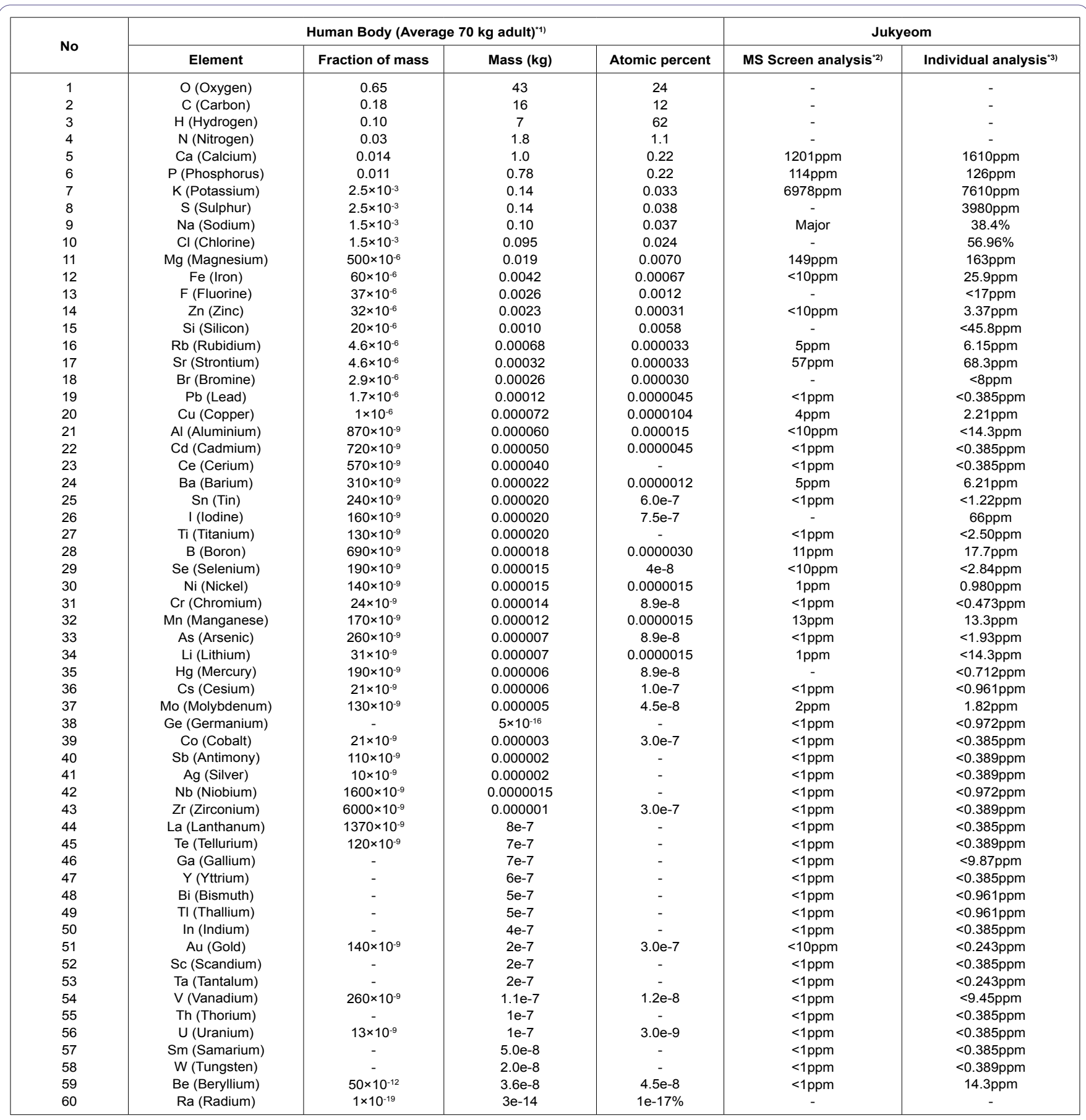

Table 4: Compositions of the human body \& the Jukyeom.

*1) Composition of the human body - Elemental composition list - Wikipedia

*2) GLI's Laboratory Report No.82972 (2015. 09.01)

*3) GLI's Laboratory Report No.83233 (2015. 09.11)

These are not solar salts or Jukyeom. The existing studies about Jukyeom also argue against the sodium-hypertension hypothesis. Yang et al., examine spontaneously hypertensive rats with systolic pressures greater than $175 \mathrm{mmHg}$ by providing Jukyeom water for four weeks. They find that the intake of Jukyeom water does not affect the systolic blood pressure, mean blood pressure, diastolic blood pressure and heart rate of rats significantly [17]. Ryu et al., also confirm that the intake of Jukyeom does not cause thirst unlike the intake of other salts. They further conclude that Jukyeom might adjust the blood pressure of patients toward the normal level irrespective of whether the patients are in hypertension or hypotension [18]. Bang et al., also show that no significant changes in blood pressures and electrolyte concentration occur before and after the ingestion of Jukyeom in their clinical trials with 13 participations [19].

A number of studies have recently refuted the relationship between sodium actually refined sodium intake and hypertension. 
M.W. Moyer argues that no concrete evidence has found for the relationship between sodium intake and hypertensions in spite of rapid developments in medical science [20]. The Institute of Medicine (IOM) also comes to the same conclusion. Unlike the emphasis on the low sodium diet prevalent for decades there exist no empirical evidence confirming that such low sodium intakes indeed lower the possibility of hypertensions. This low sodium intake might cause harmful effects on the incurrence of diabetes, hypertensions, kidney diseases and cardiovascular diseases [21].

In this study, we conduct an elemental analysis to examine Jukyeom as the source of trace elements to human body, which includes all of 60 elements (focuses on 54 measurable elements) of components of a human body.

\section{Materials and Methods}

\section{Objective of study}

Although the safety and role of Jukyeom as the source of nutrient is well examined in the exiting literatures, the exact composition of Jukyeom and its potential role as the source of trace elements to a human body has not been examined. Considering the fact that the deficiency in trace elements is regarded as one of major reasons inducing chronic disease, it is important to notice the possibility of Jukyeom as the supplier of trace elements to a human body. We further confirm the difference between Jukyeom and refined sodium since refined sodium is widely used to test the relationship between sodium and hypertension.

\section{Chemical analysis}

We employ Mass Spec Semi-Quantive Screen [22] and other optimum processes to conduct an elemental analysis for Jukyeom. This elemental analysis also includes the 13 out of 16 widely accepted toxic elements in human body; Oxygen (O), Radium (Ra) and Polonium (Po) are excluded. We conduct the elemental analysis on seven out of nine carcinogenesis, which are claimed by IARC [23]; only Radium (Ra) and Polonium (Po) are excluded. We determine total fluorine by oxygen flask combustion and ion-selective electrode [24]; total halogens or total haldes by potentiometric titration [25]; iodine by ion-selective electrode [26]; anions by suppressed ion chromatography [27]; standard test method for elements in digestates by inductively coupled plasma mass spectrometry [28]. We also adopt inductively coupled plasma atomic emission spectrometry [29] and atomic absorption spectrophotometry [30].

\section{Analysis methodology}

To identify trace elements in Jukyeom, this paper uses the ICP-MS with other proper methods. Our report is based on two different results from Japan Food Research Laboratories and Galbraith Laboratories, Inc. This paper investigates 54 measureable elements among 60 elements; this research excludes oxygen, carbon, hydrogen, and nitrogen, which consists of $96 \%$ of the human body and two radioactive elements, Polonium and Radium.

Other methods are described as follows. The measurement of $\mathrm{pH}$ in Jukyeom is based on the glass electrode method (from Japan Food Research Laboratories; JFRL) and GLI procedure S-130 (from Galbraith Laboratories). Redox potential (Oxidation-Reduction Potential; ORP) is analyzed by examining the platinum electrode method (from JFRL). In table 5, the levels of dioxin in Jukyeom and other salts are examined as well by following the Japanese guideline

\begin{tabular}{|c|c|c|c|c|}
\hline Items & $\begin{array}{c}\text { Jukyeom } \\
\text { (TEQ) }\end{array}$ & $\begin{array}{c}\text { Taean Choilyom } \\
\text { (TEQ) }\end{array}$ & *TDI (WHO) & TDI (FDA) \\
\hline PCDD & 0 & 0.000343 & & \\
PCDF & 0 & 0.000521 & & 13 \\
Co-PCB & 0 & 0.000002 & $1-4$ & \\
Homologue & 0 & 0 & & \\
Total & 0 & 0.00052 & & \\
\hline
\end{tabular}

Table 5: Dioxins analyzed result of the Jukyeom ${ }^{* 1)}$.

*TDI: Torlerable Daily Intake (pg-TEQ/kg/day)

*1) JFRL Report No.150993776001-0201(2015. 11.18)

(from JFRL). We also compare the elements in Jukyeom and other salts in table $6 \& 7$.

\section{Results and Discussion}

Table 4 reports the elemental composition of Jukyeom based on ICP-MS with other proper methods. This table mainly confirms that Jukyeom contains all trace elements of the human body while their concentration levels and composition ratios are different. This result implies that Jukyeom could be a great source of trace elements to the human body as far as its safety is ensured. Moreover, table 4 documents high calcium, lithium and potassium contents in Jukyeom. Yet, the table finds the low magnesium contents in Jukyeom as well. Such high levels of calcium and potassium are probably because Jukyeom is roasted several times in raw bamboo [31]. Jukyeom may absorb rich minerals contents from raw bamboos throughout its roasting procedure.

Table 1 examines whether the toxic elements found in Jukyeom exist or not in the human body. The table reports the results of elemental analysis for 15 toxic elements except oxygen in Jukyeom. The table also compares these 15 toxic elements in between Jukyeom and the human body. In table 1, the toxic elements found in Jukyeom are also contained in the human body. This finding is also consistent with prior studies. The existing studies found a few amount of arsenic elements in liver and kidney. Deficiencies of arsenic and cadmium are also known to cause slow growth in the human body [32]. This finding supports the safety of Jukyeom intake as the source of minerals to the human body.

Table 2 reports seven out of nine carcinogens in the human body. Radioactive elements of Radium and Polonium are excluded in this analysis. Such nine elements are selected based on the criterion of International Agency for Cancer published in 2015 [23]. The table also compares the carcinogen contents of Jukyeom with the daily allowance level of Korean Food and Drug Administration (KFDA, hereafter). Table 2 indicates that the level of carcinogen contents in Jukyeom is miniscule. The amount of carcinogen contents in Jukyeom is quite lower than the allowance level of KFDA. This finding also supports the safety of Jukyeom intake from the perspective of the level of carcinogen contents.

Table 3 investigates the difference of $\mathrm{pH}$ between Jukyeom and solar salt. Consistent with prior literature, the table shows less acidity in Jukyeom compared to ordinary solar salt. Our finding in table 3 suggests that the intake of Jukyeom is beneficial to the human body. Due to the substantial intake of animal fat, the human fluid has become more acid recently. To neutralize this acidity, the human body may have to additionally intake alkaline water [33]. The table point to the potential role of Jukyeom water intake as a neutralizer for the acidity of the human body. B.A. Teicher argues the $\mathrm{pH}$ level indicates that Bamboo salt (Jukyeom) is alkaline, which might be one the contributing factors for this [34]. 
Citation: Yoon-Chul Lee, Min-Sun Lee, Seok-Jong Jang (2016) Jang Jukyeom as the Source of Trace Elements to the Human Body: An Analysis using In-san Jukyeom. J Food Sci Nutr 2: 011.

- Page 5 of $7 \bullet$

\begin{tabular}{|c|c|c|c|c|c|c|c|}
\hline Product & Jukyeom & $\begin{array}{c}\text { Miwon Mat } \\
\text { Sogum }\end{array}$ & $\begin{array}{c}\text { Baksul Flavored } \\
\text { Salt }\end{array}$ & $\begin{array}{c}\text { Hanju Premium } \\
\text { Pure Salt }\end{array}$ & $\begin{array}{c}\text { Baksul Premi- } \\
\text { um Salt }\end{array}$ & $\begin{array}{c}\text { Shinan } \\
\text { Chonilyom Mat } \\
\text { Sogum }\end{array}$ & $\begin{array}{c}\text { Taean Chonilyom } \\
\text { Shinan Chonilyom }\end{array}$ \\
\hline $\mathrm{Na}(\%)$ & 38.5 & 34.3 & 38.7 & 38.5 & 31.8 & 35.1 & 32.6 \\
Cl & 57.14 & 55.46 & 55.26 & 57.29 & 48.44 & 54.25 & 48.83 \\
Total (\%) & 95.64 & 89.76 & 90.96 & 95.79 & 80.24 & 89.35 & 81.43 \\
\hline
\end{tabular}

Table 6: Comparison of the $\mathrm{NaCl}$ concentration in different type of salts ${ }^{* 11}$.

*1) GLI Report No. 85449(2015. 12. 09)

\begin{tabular}{|c|c|c|c|}
\hline Product Element & Jukyeom & Taean Chonilyom & Shinan Chonilyom \\
\hline Al (Aluminium) & $<19.6 \mathrm{ppm}$ & $<19.6 \mathrm{ppm}$ & $<19.8 \mathrm{ppm}$ \\
\hline $\mathrm{Ca}$ (Calcium) & $1170 p p m$ & $1260 p p m$ & 400ppm \\
\hline $\mathrm{Cl}$ (Chlorine) & - & - & - \\
\hline Cu (Copper) & $<9.79 \mathrm{ppm}$ & $<9.77 \mathrm{ppm}$ & $<9.89 \mathrm{ppm}$ \\
\hline I (lodine) & $21 \mathrm{ppm}$ & $12 \mathrm{ppm}$ & $<13 p p m$ \\
\hline K (Potassium) & 6960ppm & 2770ppm & 1350ppm \\
\hline Mg (Magnesium) & $62.2 \mathrm{ppm}$ & 9000ppm & 4960ppm \\
\hline $\mathrm{Na}$ (Sodium) & $38.5 \%$ & $32.6 \%$ & $38.5 \%$ \\
\hline S (Sulphur) & 2860ppm & $5680 \mathrm{ppm}$ & 2770ppm \\
\hline Zn (Zinc) & $<9.79 \mathrm{ppm}$ & $<9.77 \mathrm{ppm}$ & $<9.89 \mathrm{ppm}$ \\
\hline Sr (Strontium) & $52.6 \mathrm{ppm}$ & $37.2 \mathrm{ppm}$ & $35.2 \mathrm{ppm}$ \\
\hline As (Arsenic) & $<4.9 p p m$ & $<4.89 \mathrm{ppm}$ & $<4.95 \mathrm{ppm}$ \\
\hline Ba (Barium) & $<9.79 \mathrm{ppm}$ & $<9.77 \mathrm{ppm}$ & $<9.89 \mathrm{ppm}$ \\
\hline Be (Beryllium) & $<9.79 p p m$ & $<4.89 \mathrm{ppm}$ & $<4.95 \mathrm{ppm}$ \\
\hline Cd (Cadmium) & $<9.79 \mathrm{ppm}$ & $<9.77 \mathrm{ppm}$ & $<9.89 p p m$ \\
\hline Hg (Mercury) & $<4.90 \mathrm{ppm}$ & $<4.89 \mathrm{ppm}$ & $<4.95 \mathrm{ppm}$ \\
\hline $\mathrm{Pb}$ (Lead) & $<9.79 p p m$ & $<9.77 \mathrm{ppm}$ & $<9.89 p p m$ \\
\hline
\end{tabular}

Table 7: Comparison of the ingredients in Jukyeom and raw materials ${ }^{* 11}$.

*1) GLI Report No. 85449 (2015. 12. 09)

\begin{tabular}{|c|c|c|}
\hline $\begin{array}{l}\text { Jukyeom Concen- } \\
\text { tration }\end{array}$ & $\begin{array}{l}\text { Redox Potential }\left(25^{\circ} \mathrm{C} \text { vs } \mathrm{Ag} /\right. \\
\qquad \mathrm{AgCl})^{* 11)}\end{array}$ & $\begin{array}{c}\text { Remarks } \\
(\mathrm{pH})^{* 1)}\end{array}$ \\
\hline $0.9 \%$ solution & $-190 m V$ & $9.3\left(24^{\circ} \mathrm{C}\right)$ \\
\hline $5.0 \%$ solution & $-220 m V$ & $10.0\left(24^{\circ} \mathrm{C}\right)$ \\
\hline $10 \%$ solution & $-250 \mathrm{mV}$ & $10.3\left(24^{\circ} \mathrm{C}\right)$ \\
\hline $15 \%$ solution & $-330 \mathrm{mV}$ & $10.4\left(24^{\circ} \mathrm{C}\right)$ \\
\hline $20 \%$ solution & $-420 \mathrm{mV}$ & $10.5\left(24^{\circ} \mathrm{C}\right)$ \\
\hline
\end{tabular}

Table 8: Redox potential test result of the Jukyeom.

\section{*1) JFRL Report No. 15041395001-0301(2015. 09. 01)}

Table 8 conducts ORP test for Jukyeom. The result of the Table 8 also contrasts the very low levels of ORP. The ORP test is widely used to determine the level of alkaline, based on the hypothesis that water with low ORP help interactions with active oxygen. Table 8 shows that the increase of the reducing power of Jukyeom enhances as its concentration level increases. This result is opposite to that of sea salt. This difference is mainly due to the role of low molecular sulfur compounds, such as $\mathrm{SO}_{2}$. The roasting procedure of Jukyeom may affect the level of $\mathrm{SO}_{2}$ contents in Jukyeom. This increase in the reducing power of Jukyeom supports again the potential role of Jukyeom as a nutritional supplement. Many studies confirm the beneficial role of reducing power in human health conditions. For instance, Kim et al., argue the intake of Jukyeom may reduce the level of peroxide in the human body [35].

Table 7 compare the mineral contents in between Jukyeom and solar salt. Table 7 shows a substantially high level of potassium in Jukyeom compared to solar salt. Actually, the amount of potassium in Jukyeom is 2.5-5 times larger than its counterpart in solar salt. The level of magnesium is substantially lower but the level of phosphorus is far higher in Jukyeom. The higher level of phosphorus in Jukyeom is inconsistent with the existing studies such as Kim et al., [31]. Considering the antagonism between potassium and sodium, such high contents of potassium implies a lower accumulation level of sodium, which may reduce blood pressures. Because magnesium actually absorbs water in the human body, such a low magnesium level restrains the increase in blood pressures as well [36].

Table 9 shows mineral and vitamin supplements in the market generally contain less than ten kinds of minerals. Considering around 60 trace elements in the human body, it is highly unlikely that such mineral and vitamin supplements are sufficient to maintain health conditions. Furthermore, the minerals and vitamins work jointly to improve the metabolism as human body, which highlights the significance of balancing mineral intakes. This importance of balancing minerals undermines the value of mineral and vitamin supplements traded in the market as well.

\section{Conclusion}

This paper examines Jukyeom as another source of trace element supplements to the human body. The results of this paper confirm the possibility of Jukyeom as a well-balanced nutritional supplement. Even though low sodium diet is recommended nowadays, sodium actually plays a variety of beneficial roles. This paper actually confirms that Jukyeom, the roasted salt in bamboos can be used as the safe source of trace minerals to the human body. We may directly intake Jukyeom in the form of water solution or indirectly intake by using Jukyeom as a condiment for all kinds of foods. Jukyeom is also perfectly used for a variety of fermented foods such as Kimchi, soy bean paste, hot-chilli pepper paste and soy-sauce. Jukyeom is a great nutritional supplement, which help to prevent and cure a number of chronic diseases in our modern life. Our results suggest to use Jukyeom rather than refined salts in the production of processed foods, in order to provide substantial trace elements to the human body. Confirming this argument might be fruitful research directions for future studies. 
Citation: Yoon-Chul Lee, Min-Sun Lee, Seok-Jong Jang (2016) Jang Jukyeom as the Source of Trace Elements to the Human Body: An Analysis using In-san Jukyeom. J Food Sci Nutr 2: 011.

- Page 6 of $7 \bullet$

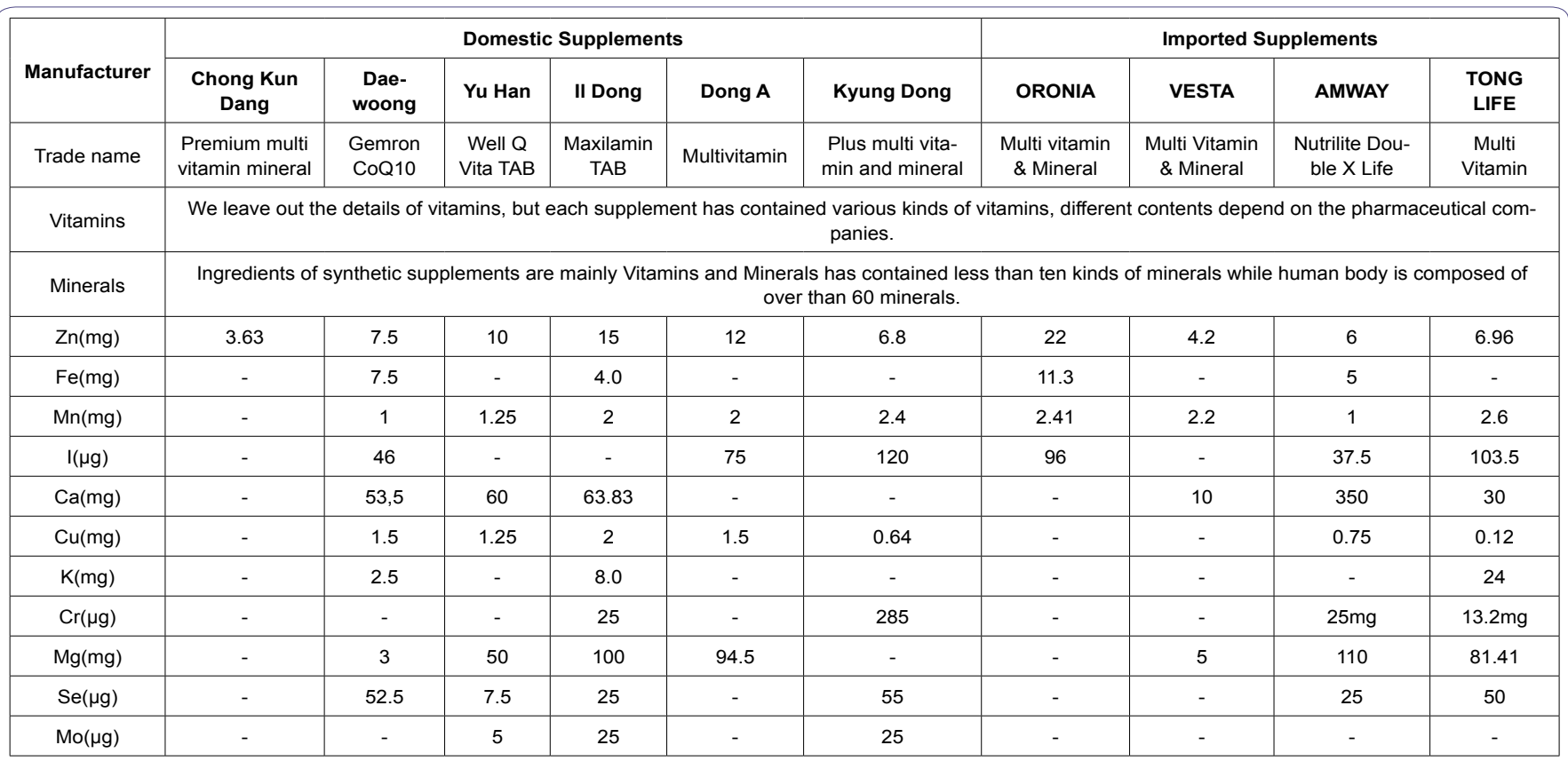

Table 9: Ingredients \& contents of nutritional supplements in domestic market.

\section{References}

1. Katsutoshi Yoshizato (1992) The function of the trace minerals in the body. Kodansha, Tokyo, Japan.

2. Murray MT, Pizzorno J (1997) The Encyclopedia of Natural Medicine. Three Rivers Press, New York USA. Pg no: 72-73.

3. Balch PA (2010) Prescription for Nutritional Healing: a practical A-to-Z reference to drug-free remedies using, vitamins, minerals, herbs \& food supplements. Avery a member of Penguin Putnam Inc., New York, USA. Pg no: 32

4. Beach R (1936) "Modern Miracle Men", Relating to Profer Food Mineral Balances. $74^{\text {th }}$ Congress $2^{\text {nd }}$ Session, Senate, Document No.264, Government Printing Office, USA. Pg no: 1-12.

5. Balch PA (2010) Prescription for Nutritional Healing: A practical A-to-Z reference to drug-free remedies using vitamins, minerals, herbs \& food supplements. Avery a member of Penguin Putnam Inc., USA.

6. Reymond W (2010) Toxic Food. Flammarion, France.

7. Walker NW (1974) Water can Undermine Your Health. Norwak Press, Prescott, USA. Pg no: 41

8. Atariakira S (2003) Tokai university graduate school, Oceanography, Marine Aquaculture. Midori Shoho, Tokyo, Japan.

9. Wikipedia, Composition of the human body.

10. Oishi M (2004) Introduction to Biology. Nippon Jitsugyo Publishing Tokyo, Japan. Pg no: 48-51.

11. Sung-Sup Shin, Jong-il Park, Heung-sik Suh (2010) Single Dose Oral Medication Toxicity Studies of the Insan Jukyeom in SD Rats. Report No.TBH1169(KG-2010-276). Pg No: 7-8.

12. Seon-ju Kim, Jin-hee Lee, Dong-min Oh (2011) 2 weeks Repetition Oral Administration studies of the Insan Jukyeom in SD Rate. Report No.TBH-1170, III. Pg no: 5,12.

13. Jun-gyou Kim, Kyung-won Seo, Bong-hun Lee, Bakchangwon, Huwan SD et al. (2002) 3 Months Repeated Dose Toxicity studies of the Bamboo Salt (Jukyeom) in Rats. J Toxicol Pub Health 18: 149-157.

14. Jong-yun Lee, Jun-yeon Lee, Hae-jin Kwon (2010) In Vitro Chromosomal Aberration Assay of the InsanJukyeom. Report No. TBH-1172 (KG-2010-282). Pg no: 9-10.
15. Jong-yun Lee, Jun-yeon Lee, Hae-jin Kwon (2011) In Vivo Micronucleus Assay of the Insan Jukyeom. Report No. TBH-1173 (KG-2010-283). Pg no: 8-9.

16. Jong-yun Lee, Jun-yeon Lee, Yo-hanJu (2011) Bacterial Reverse Mutation Test of the Insan Jukyeom. Report No. TBH-1171(KG-2010-281). Pg no: 6-7.

17. Ji-sun Yang, Ok-hee Kim, Soo-youn Chung (1999) Pharmacological Evaluation of Bamboo Salt. Journal of Applied Pharmacology 7: 178-184.

18. Hyo-lkRyu, Jun-ho Bang, Young-Hee Kim (2001) Clinical Research for Health Safety in Human Organism of the InsanJukyeom. The study reports of the department of biochemistry at Yeungnam University. Pg no: 9,17.

19. Joon-ho Bang, Byoung-yoon Park, Dong-seong Kim (2002) Effects of Bamboo Salt Ingestion on Blood Pressure and Serum Electrolytes. J Korean Soc Hygienic Science 8: 87-95.

20. Moyer MW (2011) It's Time to End the War on Salt. Scientific American.

21. Bibbins-Domingo K (2013) The Institute of Medicine Report Sodium Intake in Populations: Assessment of Evidence Summary of Primary Findings and Implications for Clinicals. JAMA Internal Medicine 174: 136-137.

22. GLI, Method Summary, Semi-Quantitative Metals Screen by Mass Spectrometry, ME-31 ICP-MS SCREEN.

23. WHO (2015) Agents Classified by the IARC Monographs, (Vols. 1-116), WHO, Geneva, Switzerland.

24. GLI Method Summary, Determination of Total Fluorine by Oxygen Flask Combustion and Ion-Selective Electrode, E9-3 Rev 15, Analyte: F.

25. GLI Method Summary, Determination of Total Halogens or Total Halides by Potentiometric Titration, E17-1 Rev 18, Analyte: $\mathrm{Cl}(\mathrm{Cl}, \mathrm{Br} \& \mathrm{I}$ as $\mathrm{Cl})$.

26. GLI Method Summary, Determination of lodine by Ion-Selective Electrode, E53-4 Rev 10, Analyte: I.

27. GLI Method Summary, Determination of Anions by Suppressed Ion Chromatography, ME-4A, Analyte: Chloride, Bromide, Nitrite, Nitrate, Phosphate, Sulfate, Fluoride, Chlorites, Chlorate, Bromate, and Oxalate.

28. GLI Method Summary, Standard Test Method for Elements in Digestates by Inductively Coupled Plasma Mass Spectrometry, ME-30, Analyte: Screen.

29. GLI Method Summary, Inductively Coupled Plasma Atomic Emission Spectrometry, ME-70 Rev 8, Analyte: 70 Elements.

30. GLI Method Summary, Atomic Absorption Spectrophotometry, ME-71 Rev 0 , Analyte: 39 Elements. 
31. Young-Hee Kim, Hyo-lkRyu (2003) Elements in Bamboo Salt and Comparision of Its Elemental Contents with Those in Other Salts. Yakhak Hoeji 47 135-141.

32. Yoshizato K (1992) The function of the trace minerals in the body. Kodansha, Tokyo, Japan. 10: 38.

33. Young RO, Young SR, Yu-Ri Kang (2007) The pH Miracle for Weight Loss Woongjin Think Big Co. Ltd., Seoul Korea. Pg no: 29-75.
34. Beverly A (1995) Efficacy of Orally Administered Mineral Salt (Jukyeom) against the EMT-6/Parent Tumor, W/or W/O Radiotherapy and Toxicology study for Human Oral Consumption.

35. Hag-Lyeol Kim, Seong-Jae Lee, Jung-Hee Lee, In-Cheol Kim (2014) Sulfur Dioxide, Mineral Contents and Physicochemical Properties Generated During Manufacturing of Bamboo Salt. J Korea Soc Food Sci Nutr 43: 1248-1256.

36. Won-Jung Lee (1999) Salt and Hypertension. Journal of the East Asian of Dietary Life 9: 378-385. 